\title{
THE EXPERIMENTAL METHOD AND CFD STUDY OF THE BARE HULL FORM OF UNDERWATER VEHICLE AT NEAR SURFACE CONDITION
}

\author{
Thu Han Tun and Ye Thet Htun \\ Marine Mechanical Department, Myanmar Maritime University Thanlyin, Yangon Region, The Republic of the \\ Union of Myanmar, e-mail: dr.thuhantun@gmail.com, yethet11@gmail.com
}

Received Date: December 11, 2019; Revised Date: April 21, 2020; Acceptance Date: September 10, 2020

\begin{abstract}
Hull form selection, resistance and powering are important in designing underwater vehicle. An underwater vehicle bare hull form is based on the five parameters due to the interaction between the propeller and the hull. When they are running on the surface condition, there will be problems likely as surface vessel, but the main hull of the underwater vehicle is below the waterline with low freeboard. The underwater vehicles are operating with high speed at a high Froude Number. Therefore, the wave making component becomes important in surface resistance. The wave making resistance of the underwater vehicle model at surface condition is analyzed by using CFD tools. Friction component of resistance is calculated by using ITTC' 57 correlation line. The flow around the ship's hull is complicated, so that model experiments are still the most reliable data source on ship resistance determination. The bare hull form of underwater vehicle resistance is based on the model experiments and CFD results. The towing mechanism arrangement should be considered at model. Therefore, towing mechanism is designed for model testing. This paper discusses the towing method and result between model test and CFD. This paper also makes comparison of wave formation Towing tank test and CFD at various speeds. The model was tested with bare hull form of underwater vehicle in the Ship Model Towing Tank at Marine Hydrodynamics Centre, Myanmar Maritime University. CFD analysis is also carried out and the results are compared for surface condition. The three software packages XFLOW, XMESH and XPAN are used for CFD simulations. The comparison of results shows that the coefficient differences are less staggered based on the speed.
\end{abstract}

Keywords: CFD, Model experiment, Resistance, Towing tank, Underwater vehicle

NOMENCLATURE

LOA Length overall $(\mathrm{m})$

LWL Length waterline (m)

LB Bow length (m)

LC Cylinder length (m)

LCS Conical Stern length (m)

$\gamma \quad$ Conical Stern angle (degree) 


$\begin{array}{ll}\text { DH } & \text { Hull Diameter (m) } \\ \text { T } & \text { Draft (m) } \\ \Delta & \text { Displacement (tons) } \\ \text { V } & \text { Speed of vessel (m/s) } \\ \text { Rt } & \text { Total resistance (N) } \\ \text { CT } & \text { Total resistance coefficient } \\ \text { CF } & \text { Frictional resistance coefficient } \\ \mathrm{CR} & \text { Residual resistance coefficient } \\ \mathrm{Re} & \text { Reynolds number } \\ \rho & \text { Density of water (ton/m3) } \\ \mathrm{S} & \text { Wetted surface of ship (m2) }\end{array}$

\section{Introduction}

Hull form selection, resistance and powering are important in designing underwater vehicle. Model testing is carried out traditionally to predict the resistance and power at the near surface condition. Model is bare hull form without any appendages. Appendages resistance also should be considered for prediction of the resistance.

Now a day CFD tools are widely used for prediction of ship's resistance and power. However the flow around the ship's hull is complicated, so that model experiments are still the most reliable data source on ship resistance determination. The model experiments are carried out in the Ship Model Towing Tank at Marine Hydrodynamics Centre, Myanmar Maritime University [1]. Towing tank size established 2011 made in UK (CUSSON Technology) is $60 \mathrm{~m}$ in length, $4 \mathrm{~m}$ in breadth and $4 \mathrm{~m}$ in depth. Maximum carriage speed is 4 $\mathrm{m} / \mathrm{s}$. CFD codes are also used in design step, validation of the results is carried out by comparing the model test results.

\section{Objective}

This paper focuses on towing mechanism which arranged for model testing with bare hull form, comparing the total resistance of underwater vehicle model and to make verification for model tests results with CFD results.

\section{Study area}

Underwater vehicles are designed to work under the water but they have to work at the water surface for many reasons. So the resistance of the underwater vehicle operating at the water surface is one of the major problems in designing that kind of vehicles. Their resistance behavior at the water surface is similar to those of normal surface ships, but underwater vehicles have low freeboard with majority of the displacement is below the water surface. The operating speed of 
the underwater vessels is high. They are also operating at high Froude Number, so the wave making component becomes dominant in surface resistance [2].

By towing scale models, the resistance can be measured and using appropriate scaling laws, the resistance of the full scale vessel can be predicted.

Model of $1.536 \mathrm{~m}$ in length is fabricated with wood and tested in model basin at Myanmar Maritime University. Total resistance of the model is calculated from the towing test results by using Froude's Law of Comparison. In order to calculate the underwater vehicle model total resistance non-dimensional coefficients have been used [3]. The residual resistance is found by the pressure distribution about the hull because of the waves and eddies generated by the vessel's motion. Therefore, the wave making resistance of the underwater vehicle model at surface condition is analyzed by using CFD tools. Friction component of resistance is calculated by using ITTC' 57 correlation line and coefficient of total resistance is counted by as below.

$$
C T=C F+C R
$$

$$
C_{F}=\frac{0.075}{\left(\log _{10} \mathrm{R}_{\mathrm{e}}-2\right)^{2}}
$$

In general, the resistance of a vessel to motion through water can be calculated in the following formulation:

$$
R_{t}=\frac{1}{2} C_{T} \rho S V^{2}
$$

\section{Methodology of Study}

\section{Determining the Main Dimensions}

An underwater vehicle bare hull form is based on the following parameters due to the interaction between the propeller and the hull -

- The fineness ratio

- $\quad$ Prismatic coefficient

- $\quad$ Nose radius

- Tail angle and

- The position of the maximum section

Dimensions of underwater vehicle model in this paper are shown in Table 1 with parallel middle body form. Relation L/D is equal to 7.718 because of limitation of testing arrangement and model making by hand. Main hull is cylindrical shape and stern is conical as shown in Figure 1. 


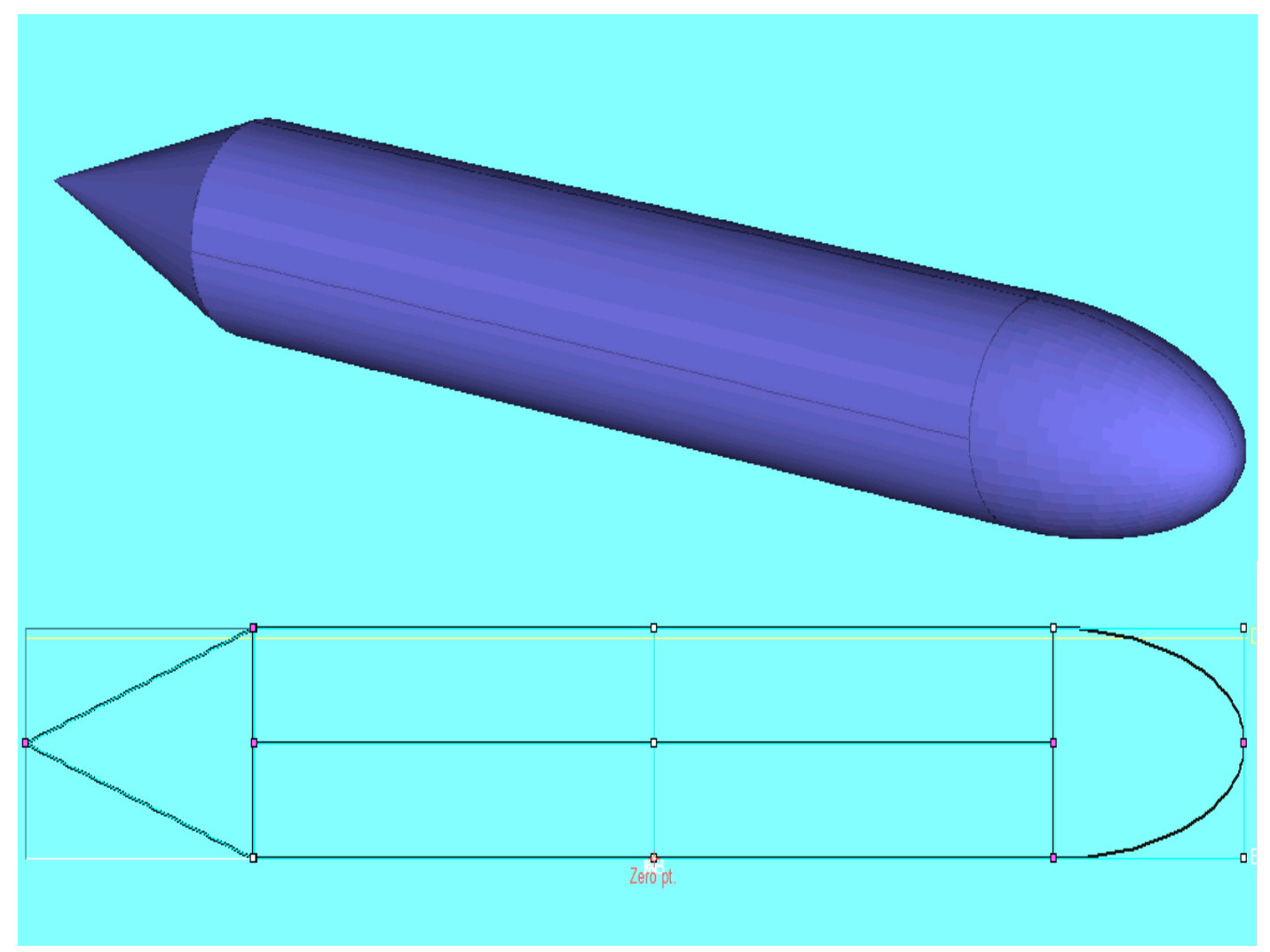

Figure 1. Model of underwater vehicle

\section{Table 1. Main Particulars of Model at Design Condition}

\begin{tabular}{lc}
\multicolumn{1}{c}{ Main Particulars } & Unit \\
\hline Overall length, LOA (m) & 1.536 \\
Hull Diameter, $\mathrm{D}_{\mathrm{H}}(\mathrm{m})$ & 0.199 \\
Displacement, $\Delta$ (tons) & 0.27 \\
Bow length, LB (m) & 0.24 \\
Cylinder length, LC (m) & 1.02 \\
Conical Stern length, LCS (m) & 0.3 \\
Draft, T (m) & 0.178 \\
Conical Stern angle, $\gamma$ (degree) & 16.7 \\
\hline
\end{tabular}

\section{Model Making and Towing Mechanism}

Fabricated wooden model without appendages are shown in Figure 2. 


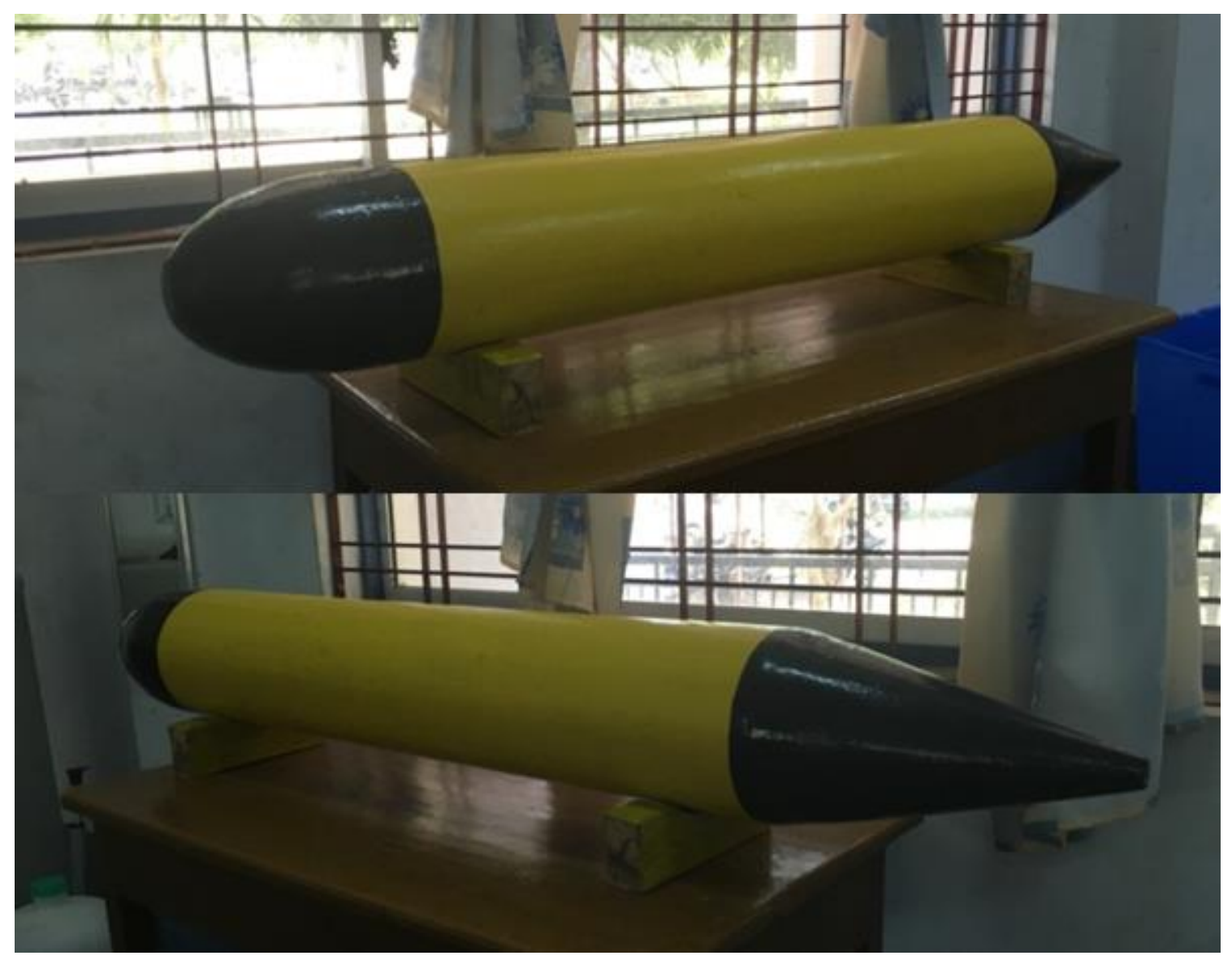

Figure 2. Fabricated wooden model

When model without appendages is testing in towing tank at near surface condition, even keel condition cannot be controlled. Therefore, the towing mechanism arrangement should be considered at model as shown in Figure 3. Elements of towing mechanism are listed in detail as the following Table 2 .

\section{Table 2. List of Towing Mechanism}

\begin{tabular}{lll} 
Symbol & \multicolumn{1}{c}{ Items } & \multicolumn{1}{c}{ Function } \\
\hline White ropes & $\begin{array}{l}\text { To lock the pitching motion (2 numbers for bow } \\
\text { and stern) }\end{array}$ \\
Guide arm fit pins & $\begin{array}{l}\text { To ensure the straight line position on flow (2 } \\
\text { numbers for bow and stern) }\end{array}$ \\
$\begin{array}{l}\text { Load cell 40kg } \\
\text { (sometimes called a } \\
\text { strain gauge) }\end{array}$ & $\begin{array}{l}\text { To measure the resistance of model (attached to } \\
\text { model) }\end{array}$ \\
$\begin{array}{l}\text { Vertical slipway or } \\
\text { towing post }\end{array}$ & $\begin{array}{l}\text { To measure the heaving motion and tow the } \\
\text { model by carriage. }\end{array}$
\end{tabular}




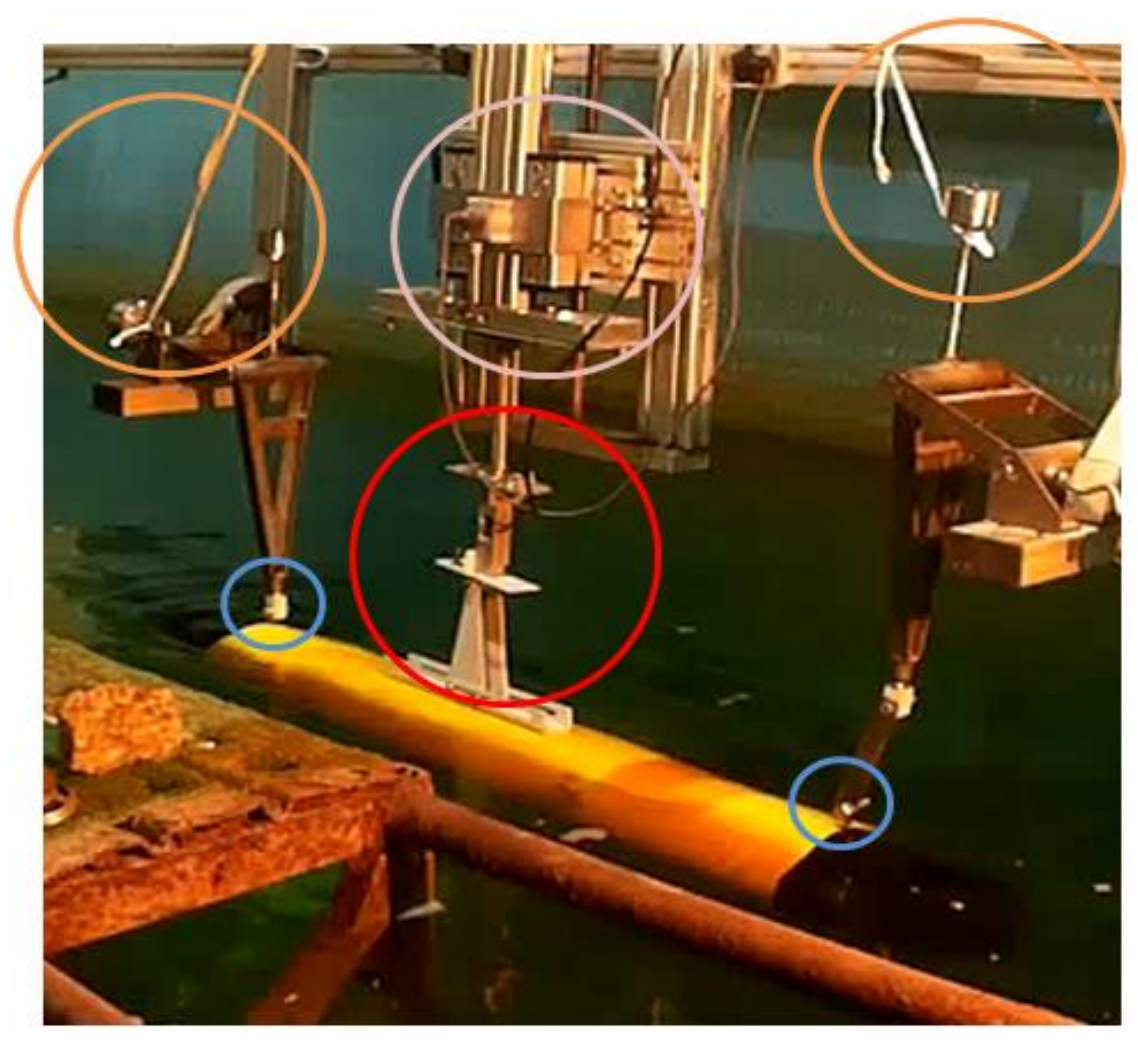

Figure 3. Towing mechanism arrangements

\section{Experimental Approach}

Two test case studies have been carried out for the speed range of 0.5 to $2.5 \mathrm{~m} / \mathrm{s}$. There are results in Table 3 below for near surface condition.

Table 3: Model Resistance Test

\begin{tabular}{cc} 
Speed of Vessel V $(\mathbf{m} / \mathbf{s})$ & Total Resistance of Model $\mathbf{R}_{\mathbf{t}}(\mathbf{N})$ \\
\hline 0.5 & 1.4 \\
0.8 & 3.47 \\
1 & 6 \\
1.2 & 6.5 \\
1.4 & 5 \\
1.6 & 8 \\
1.7 & 14 \\
1.8 & 16.5 \\
1.9 & 22.5 \\
2 & 25.5 \\
2.1 & 27 \\
2.2 & 30 \\
2.5 & 32 \\
\hline
\end{tabular}




\section{Numerical Approach}

The complexity of the flow around ship's hull, model experiments are still the most reliable data source on ship resistance determination; nevertheless, numerical methods have strongly advanced in this field, so that a combined use of both model tests and CFD codes can be very useful for ship design and for understanding the ship hydrodynamics [4].

Numerical computations are carried out around vessel using the code SHIPFLOW. The three software packages XFLOW, XMESH and XPAN are used for simulations. XPAN solver uses potential-flow panel method based on Rankine sources [5, 6] with hull and nonlinear free-surface boundary conditions [7] by discretizing the hull and the free-surface by flat quadrilateral panels. The main hull has 51 grid sections and 16 grid points. The free surface is paneled by 50 stations in longitudinal direction and 12 grid points presented in Figure 4.

As the model test was carried out with fixed condition (locked for pitching motion), the CFD simulation was also carried with fixed model to get the fixed trim and sinkage result. CFD simulation is carried out for the model from the speed range of 0.5 to $1.8 \mathrm{~m} / \mathrm{s}$. Figure 5 (a to c) shows the comparison of wave formation of model test and CFD simulation at various speeds.

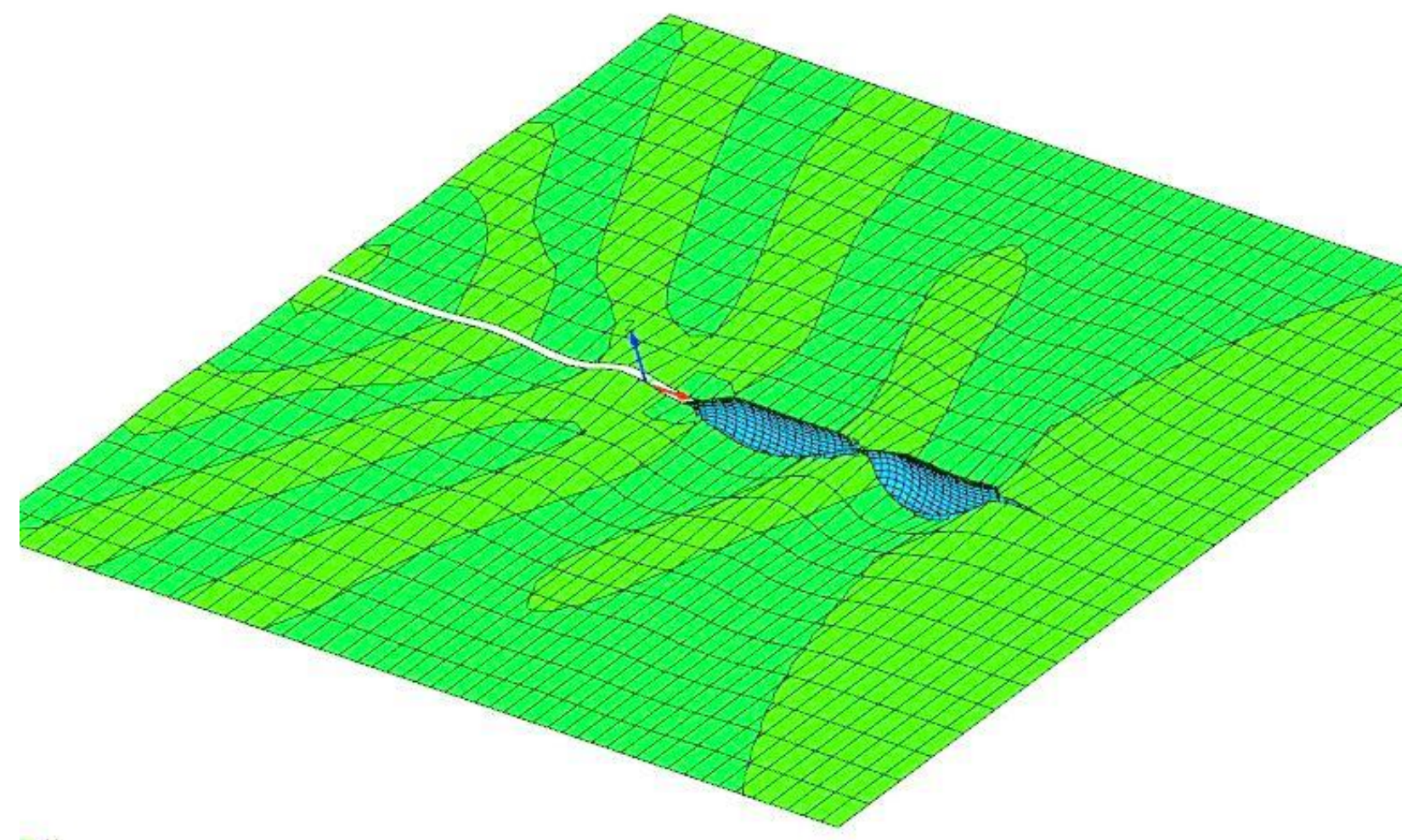

Figure 4. Generated mesh of model 


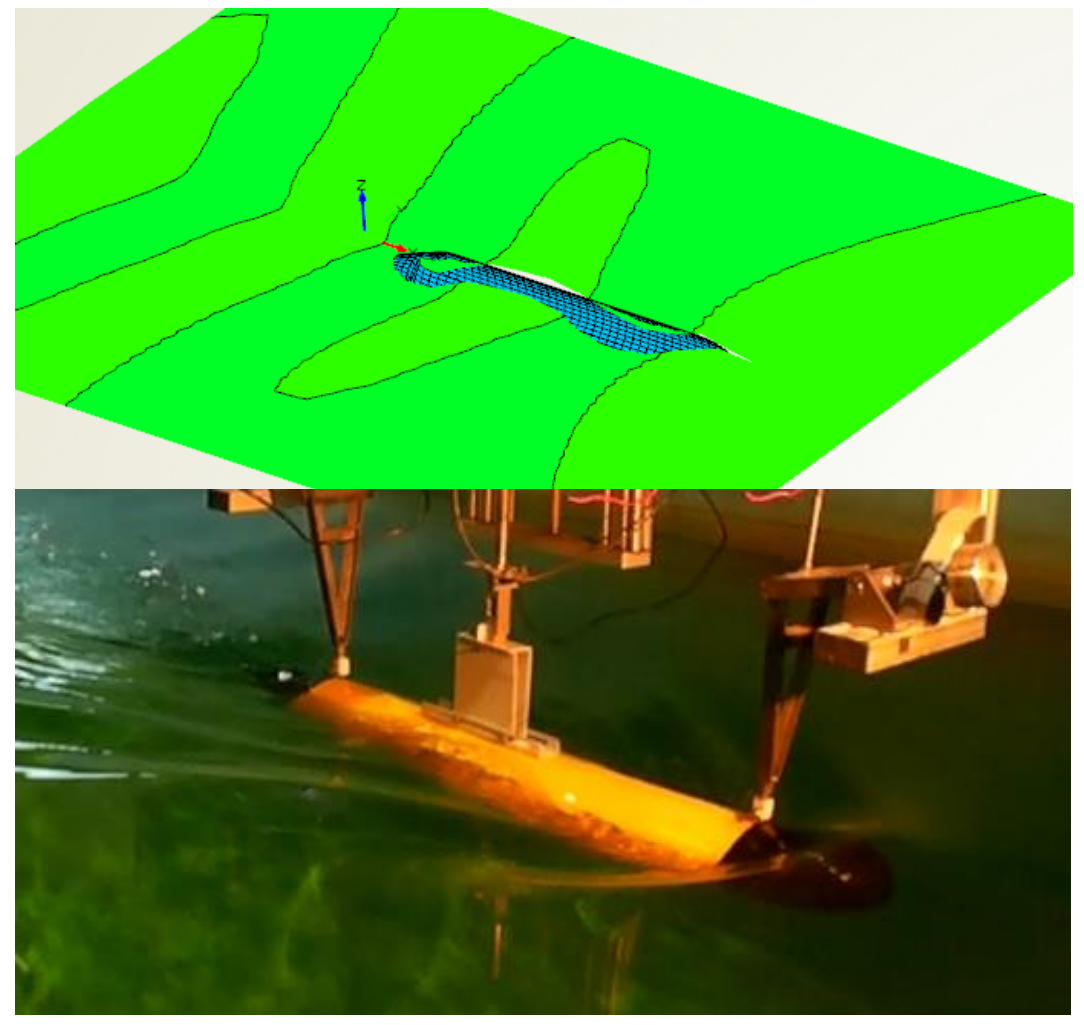

Figure 5(a). Towing tank test and CFD simulation with $1 \mathrm{~m} / \mathrm{s}$

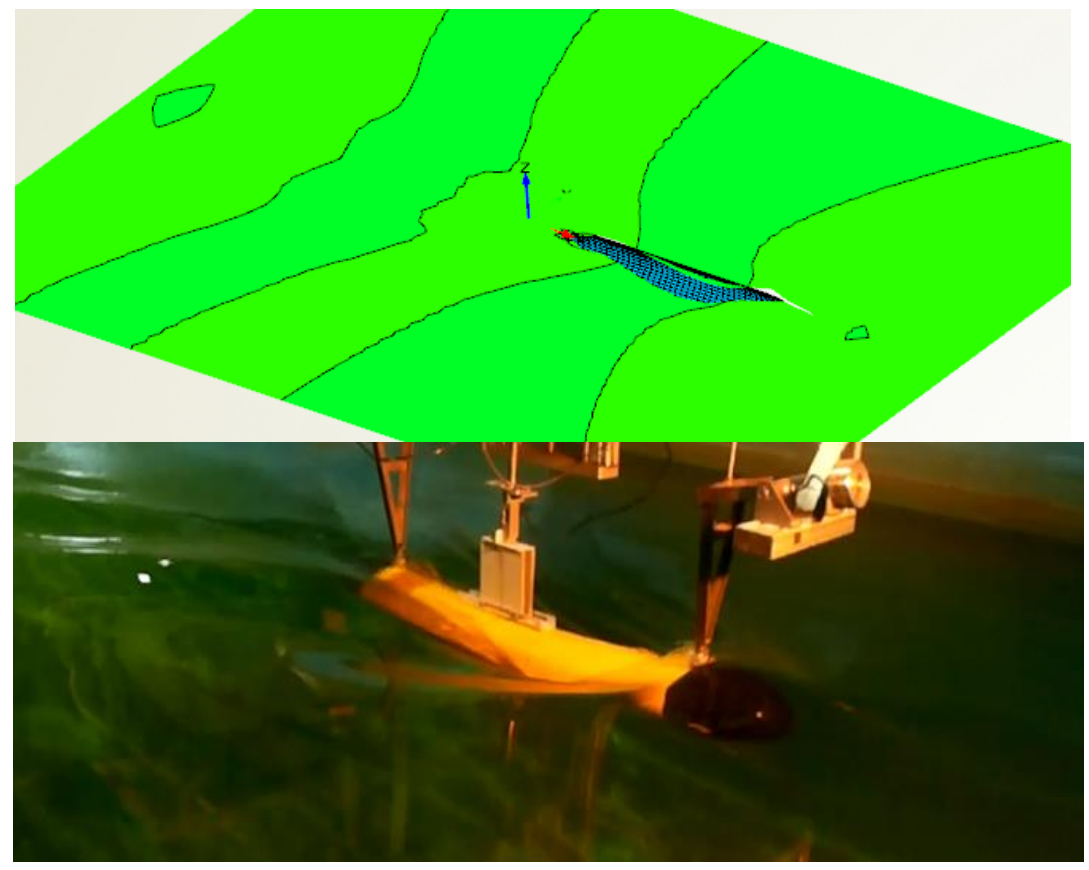

Figure 5(b). Towing tank test and CFD simulation with $1.4 \mathrm{~m} / \mathrm{s}$ 


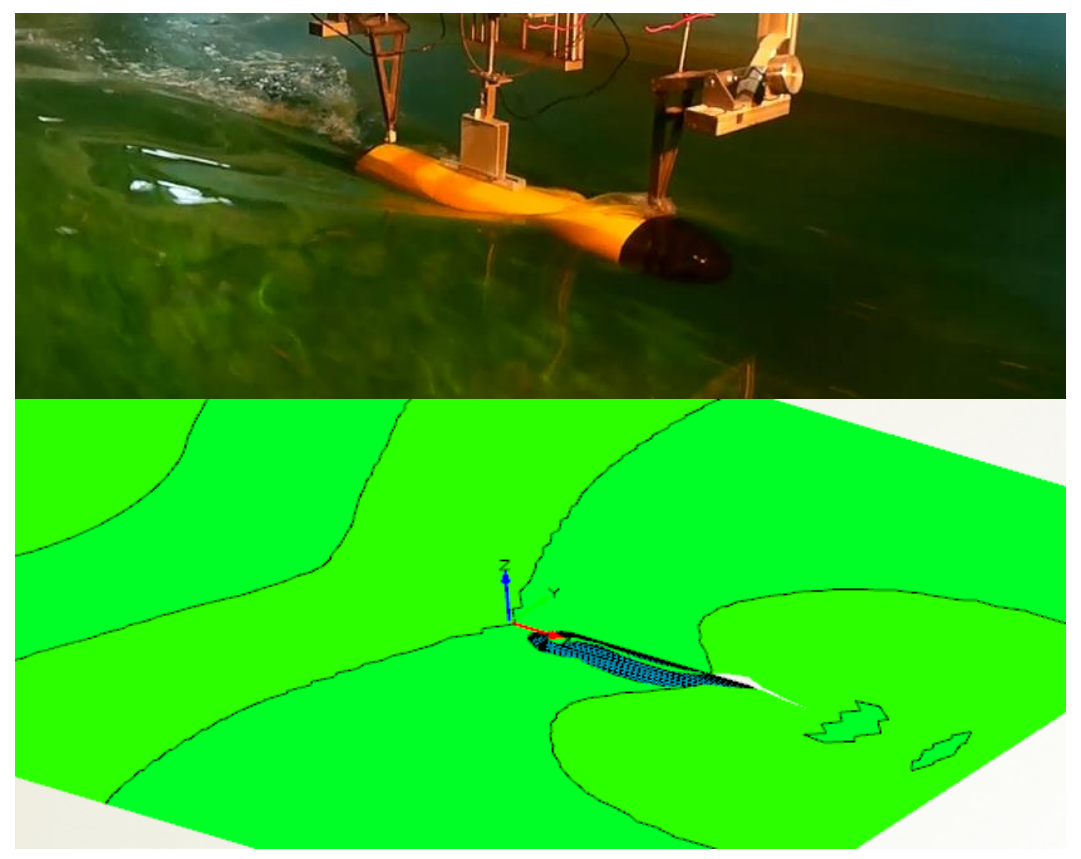

Figure 5(c). Towing tank test and CFD simulation with $1.8 \mathrm{~m} / \mathrm{s}$

Figure 5. Comparison of wave formation Towing tank test and CFD at various speeds

\section{Result Comparison}

The resistance comparison of underwater vehicle is carried out for the speed of 0.5 to $1.8 \mathrm{~m} / \mathrm{s}$. The results are compared in Figure 6. According to the results, the resistance behavior for model test is not differing from that of CFD result. At the lower speeds, resistances of the model test are higher than CFD results, but at the higher speeds, model resistances become lower.

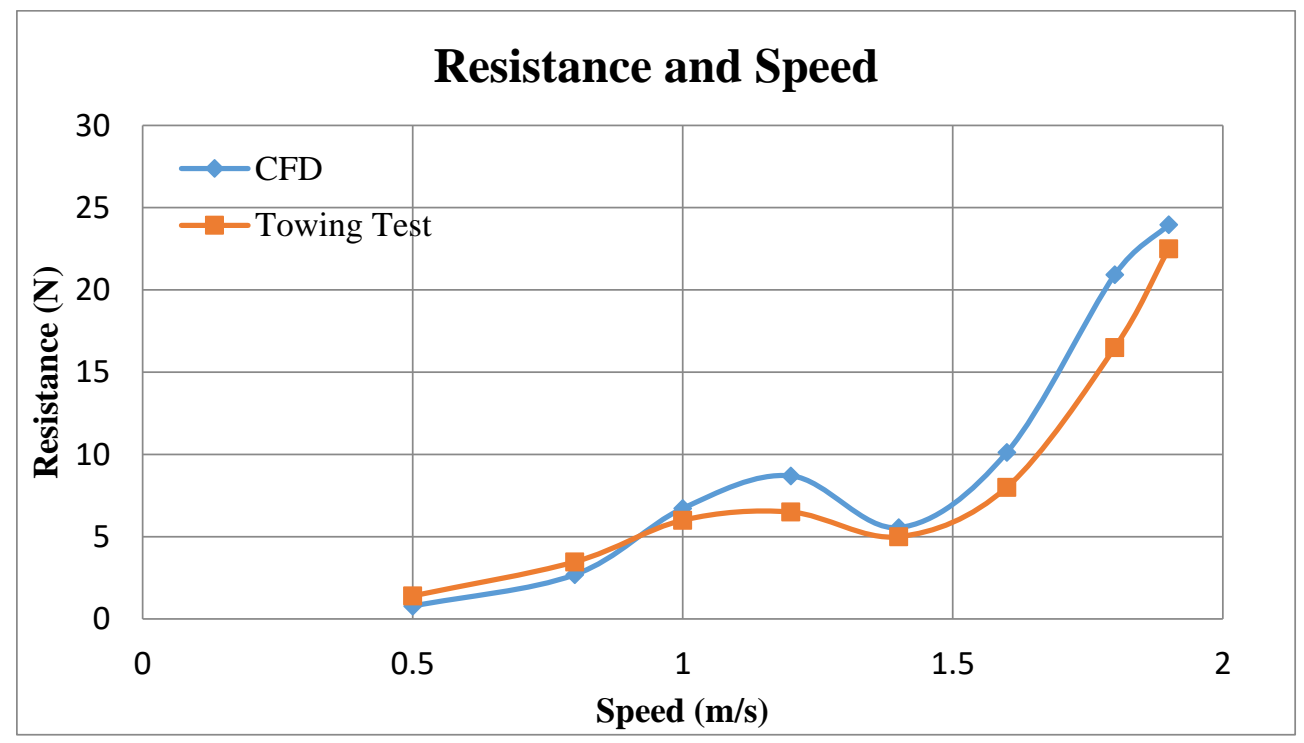

Figure 6 comparison of CFD and Towing test of ship resistance without appendages. 


\section{Conclusions}

Towing test analysis was carried out for the model with fixed trim and pitch condition. Then CFD analysis was also carried out with fixed model condition. The model test results are compared with CFD results and the comparison shows that experimental results and CFD results have good agreement for near surface condition. At the higher speed, hydrodynamic forces acting on the vehicle will become larger and so, it's still needed to consider the hydrodynamic effect of the model in freely moving condition. In the further study turbulent layer with RANS solver should be calculated. After calculating the hydrodynamic effect of the model, hydroplane should be attached to ensure for fixed trim and pitch condition.

\section{Acknowledgements}

The authors would like to express their thanks to the staffs for all their support during the experimental model tests.

\section{References}

[1] International Towing Tank Conference (ITTC), Recommended Procedures and Guidelines, Resistance Test, Revision 03 (ITTC 7.5-02-02-01), 2011.

[2] R. Burcher, and L. Rydill, Concepts in Submarine Design, Cambridge Ocean Technology Series, 1995.

[3] C.B. Barrass, Ship Design and Performance for Masters and Mates, Elsevier ButterworthHeinemann, 2004.

[4] D.G.M. Watson, Practical Ship Design, Elsevier Science Ltd., 1998.

[5] F. Capizzano, A. Migali, S. Miranda and C. Pensa, "Experimental and numerical study on the efficiency of trimaran configuration for high-speed very large ship," In The $6^{\text {th }}$ Symposium on High Speed Marine Vehicle (HSMV), Symposium conducted in Baia, Naples, Italy, September 2002.

[6] A. Dey, A Study of a Two Dimensional Flow around a Hydrofoil by Rankine Source Panel Method Using a Computer Program Based on C++, Thesis (Bachelor's), Department of Naval Architecture and Marine Engineering, BUET, Dhaka, Bangladesh, 2013.

[7] M.S. Nizam, "Computation of Wave-Making Resistance of Multihulls Using a Surface Panel Method," Thesis (Master's), Department of Naval Architecture and Marine Engineering, BUET, Dhaka, Bangladesh, 2011.

[8] M.M. Karim, and N. Naz "Computation of hydrodynamic characteristics of ships using CFD," International Journal of Materials, Mechanics and Manufacturing, Vol. 5, No. 4, pp.219-223, 2017.

[9] M.M. Karima, and N. Naza "Computation of flow field around ship hull including self propulsion characteristics at varying rudder positions," In: The 10th International Conference on Marine Technology, MARTEC, 2016.

[10] J.E. Choi, K.S. Min, J.H. Kim, S.B. Lee, and H.W. Seo, "Resistance and propulsion characteristics of various commercial ships based on CFD results," Ocean Engineering, Vol. 37, pp. 549-566, 2010.

[11] S. Tarafder, and K. Suzuki, "Numerical calculation of free-surface potential flow around a ship using the modified Rankine source panel method," Ocean Engineering, Vol. 35, pp. 536-544, 2008. 